\title{
Nem tudo brilha na produção de jóias de Limeira - SP
}

\author{
Rodolfo Andrade de Gouveia Vilela \\ UNIMEP, CEREST Piracicaba \\ Marcos Antonio Libardi Ferreira \\ Consultor
}

\begin{abstract}
Resumo
Limeira-SP é uma cidade onde opera um dos principais pólos de produção de jóias e bijuterias, que tem como característica o uso da mão-de-obra informal nos domicílios, nas atividades de montagem, soldagem e cravação de peças. Compreender o funcionamento do setor bem como identificar os riscos à saúde dos trabalhadores são os objetivos do artigo. Foi aplicado um questionário em 22 escolas da Rede Estadual de Ensino. Foi constatado que $27 \%$ dos alunos trabalham montando e soldando jóias e bijuterias, uma população de 8.340 indivíduos, dos quais $20 \%$ dos estudantes possuem idade abaixo de 17 anos (erro amostral de 5,7\%). Os alunos referem queixas de dores em membros superiores, existindo correlação entre trabalhar com jóias e bijuterias e as citadas queixas, indicando a existência de riscos de Lesões por Esforços Repetitivos - LER. Os resultados indicam a necessidade de políticas públicas e esforço da sociedade para regular e encontrar alternativas sustentáveis para o setor.
\end{abstract}

\section{Palavras-chave}

Produção de jóias e bijuterias, trabalho infantil, informalidade, riscos à saúde do trabalhador.

\section{Not everything shines in the manufacture of jewels in Limeira - SP}

\begin{abstract}
In the city of Limeira - SP is located one of the main poles of jewel and jewelry production. One of this manufacture's characteristics is the use of informal labor force having the craftsmen working at their homes in activities of assemblage, welding and carving of pieces. The aim of this paper is to understand the operation of this sector as well as to identify the risks to the workers' health. A questionnaire was passed out in 22 State schools. It was verified that 27\% of the students work setting up and welding jewels and jewelries, a population 8.340 individuals, of which $20 \%$ of the students below 17 years of age [sampling error of 5.7\%). The students complain of pains in superior members, correlated with the work with jewels and jewelries. The mentioned complaints points out to the risk of Repetitive Strain Injury - RSI. The results indicate the need of public policies and effort of the society to regulate and to find sustainable alternatives for the sector.
\end{abstract}

Key words

Jewels, jewelry, infantile work, informality, risks to the worker's health. 


\section{INTRODUC̣̃̃O}

O município de Limeira situa-se no interior do Estado de São Paulo a $154 \mathrm{~km}$ da Capital, junto a importante entroncamento rodoviário formado pelas Rodovias Anhanguera, Washington Luiz e Bandeirantes. Possui uma população de 270.000 habitantes e 1.266 indústrias de transformação. A estrutura industrial da cidade tem como principais ramos de atividade a produção de papel, chapéus, equipamentos agrícolas, máquinas-ferramentas, sistemas de freios, rodas, escapamentos e jóias e bijuterias (IBGE-2004). O município apresenta elevado índice de informalidade da força de trabalho. Segundo levantamento do IBGE, senso demográfico de 2000, a população em idade economicamente ativa do Município possui 103.241 pessoas. Possuem carteira assinada 49.379 trabalhadores e 21.613 são ocupados por conta própria. Segundo o Censo de 2000 o município conta com uma população de 48.114 habitantes na faixa de 10-19 anos de idade (PREFEITURA MUNICIPAL DE LIMEIRA, 2006, base IBGE 2000). aos trabalhadores a devida proteção do Estado (ANDRADE GONÇALVES e THOMAZ JR., 2002).

O trabalho em domicílio, se comparado com os empregos usuais do setor industrial, pode ser considerado como de baixa qualidade. Freqüentemente sem proteção da legislação trabalhista, oferecendo raríssimas oportunidades de treinamento e ascensão funcional, é uma ocupação extremamente precária (LAVINAS et al., 1998).

A informalidade contribui para eliminar os encargos sociais, uma vez que todos esses trabalhos são realizados sem nenhum tipo de contrato, eliminando qualquer tipo de vínculo trabalhista entre o contratante e o contratado. Os levantamentos da Relação Anual de Informações Sociais revelam que em 1989 havia 49.309 empregos formais em Limeira-SP, número este que cai para 42.013 empregos em 1999, com diferencial absoluto de $-14,44 \%$ no período (RAIS, 2000). No entanto, a produção de jóias veio crescendo significativamente. De 1989 a 2001 foi registrado no País aumento na produção de 10 para 25 t/ano, o que fundamenta a suposição de um aumento da informalidade nesse período (GFMS, 2001). Segundo Assunção e Dias (2002) a lógica da produção nos dias atuais expulsa adultos e incorpora crianças. Ao lado da diminuição contundente dos níveis de emprego, as estatísticas do IBGE mostram o crescimento do trabalho infanto-juvenil organizado sob diferentes formas: terceirização, subcontratação em cascata, em regime de exploração familiar, etc.

As crianças e adolescentes inseridos no meio

O Brasil é um dos maiores produtores e exportadores de jóias folheadas do mundo. A cidade de Limeira-SP representa o maior pólo da América Latina. Países como Coréia, Peru e Chile são consumidores dos folheados brasileiros. Com o desenvolvimento do mercado consumidor, as indústrias do setor iniciaram em Limeira-SP um sistema de produção peculiar, tendo a terceirização de etapas importantes do processo produtivo como uma das saídas para a competitividade. Com a terceirização, os trabalhos de montagem, soldagem e cravação foram em grande medida transferidos para os domicílios, envolvendo parentes, crianças e adolescentes neste processo.

Segundo Suzigan et al. (2000), a Prefeitura Municipal de Limeira estimou que há de 15.000 a 20.000 postos de trabalho, considerando os formais e os informais, na indústria de pedras, jóias e bijuterias de Limeira-SP ${ }^{1}$.

A migração da força de trabalho do campo rumo à cidade foi considerada a principal determinante do crescimento do setor informal e precário no meio urbano nos países em desenvolvimento. A terceirização e precarização são fenômenos globais associados à reestruturação produtiva e à redução de políticas governamentais que deixam de conferir familiar participam sem dúvida nenhuma dessa problemática. Em 2001, 8,5\% das crianças e jovens entre 5 e 15 anos de idade trabalhavam no Brasil, perfazendo um total de pouco mais de 3 milhões, o que representa $8,5 \%$ das pessoas nesta faixa de idade. Entre os que têm entre 16 e 17 anos são quase 2,4 milhões, ou $35 \%$ da população com esta idade (KASSOUF, 2004 com base nos dados do PNAD-IBGE, 2001).

Graziani, citada em Campos et al. (1999), afirma que “infância é um tempo para brincar e através da brincadeira entrar no mundo dos adultos, não de forma imediata, mas simbólica". Quando uma criança brinca, ela percebe e imita o mundo dos adultos, elaborando medos, sentimentos e conflitos. Dessa forma, a atividade lúdica é um direito e uma necessidade. A coordenação e a habilidade motora são desenvolvidas pelas brincadeiras que, além disso, servem para ensinar a conviver com outras pessoas e desenvolver a auto-estima.

Tentando entender o que leva as famílias a inserirem suas crianças no mercado de trabalho, quando têm opções de estudo, e também verificar os efeitos do trabalho precoce a curto e longo prazo, tanto para o indivíduo como para a sociedade, alguns autores concluem que geralmente os pais são 
altruístas em relação aos filhos. Ou seja, eles só irão inserir os filhos no mercado de trabalho se a sobrevivência da família estiver ameaçada. Assim, os principais determinantes do trabalho infantil, pelo lado da oferta, são a pobreza, seguida da educação dos pais, da baixa atratividade da escola e de componentes culturais (KASSOUF, 2004).

Estudos do Niosh (1997) sobre os efeitos do trabalho das crianças e adolescentes partem de uma premissa básica da pediatria de que as crianças e os jovens não são adultos em miniatura. A maioria do sistema biológico do corpo humano não está madura até a idade de 18 anos. Embora os adolescentes sejam mais parecidos com os adultos do que com as crianças de menor idade, seus corpos ainda estão em crescimento e maturação. Muita diferença em termos de anatomia, fisiologia, psicologia os distingue dos adultos. Estas diferenças podem determinar a exposição específica aos fatores de risco para acidentes e lesões ocupacionais. Os estudos revelam que os adolescentes submetidos ao estresse físico acentuado têm maior freqüência de fraturas. A alta taxa de crescimento dos jovens (estirão) é acompanhada da pouca coordenação motora, que pode contribuir para o aumento do risco de acidentes de trabalho. Os jovens têm maior necessidade de sono que os adultos, ou seja, o padrão de $8 \mathrm{~h}$ de sono só é observado a partir dos 18 anos, o que é dificultado quando os jovens estão trabalhando. Um regime pesado de trabalho pode intensificar as necessidades de sono, e caso este não seja plenamente cumprido, pode resultar em transtornos de sono, fadiga, e altas taxas de acidentes durante o trabalho (NIOSH, 1997).

No aspecto emocional, como os jovens possuem ainda menor possibilidade de defesa e reação, as características dos sistemas produtivos se tornam muitas vezes incompatíveis com as capacidades psicofisiológicas das crianças e adolescentes (ASSUNÇÃO; DIAS, 2002).

No tocante aos efeitos negativos que o trabalho precoce pode induzir nesta população, cabe destacar as incompatibilidades da capacidade muscular, do estado do esqueleto, do equilíbrio motor e a necessidade reparadora do sono como mencionado anteriormente. O relacionamento da criança com seu ambiente transcende o do adulto. Segundo Assunção e Dias (2002) citando Marcondes (1992), os seres vivos jovens têm um ponto de vulnerabilidade máxima ao ambiente, que decresce ao longo do processo de crescimento, mas permanece relevante por muitos anos. Quanto mais jovem a criança mais depende do meio ambiente e mais sensível às suas agressões. Enquanto o adulto reage, briga, foge e até mata na busca de sua adaptação, a criança precisa ser protegida.

O Estatuto da Criança e do Adolescente do Brasil (ECA) é uma legislação comparável às mais avançadas dos países desenvolvidos em relação à idade mínima de ingresso no mercado de trabalho, equiparando-se aos Estados Unidos e à França. Na Inglaterra, por exemplo, a idade mínima é de 13 anos, na Bélgica e na maioria dos países da América Latina, é de 14 anos. Em países como Suíça, Alemanha, Itália e Chile, a idade mínima de trabalho é de 15 anos (ILO, 1998).

\section{A renda obtida varia de $\mathrm{R} \$ 9,00$ a $\mathrm{R} \$ 20,00$ pessoa por dia (janeiro/2005).}

No Brasil, segundo o artigo 2o da Lei 8.069 (BRASIL, 1990), que trata do Estatuto da Criança e do Adolescente, considera-se criança a pessoa até doze anos de idade incompletos, e adolescente aquela entre doze e dezoito anos de idade. Em dezembro de 1998, o Congresso Nacional aprovou emenda constitucional estabelecendo que o trabalho noturno e perigoso à saúde "é proibido para crianças menores de 18 anos de idade enquanto qualquer forma de trabalho é proibida a menores de 16 anos salvo na condição de aprendiz, a partir de 14 anos"(KASSOUF, 2004). Como indicado na Convenção $\mathrm{n}^{-} 138^{2}$ da OIT, trabalho perigoso é aquele que pode causar danos à saúde, segurança ou à moral das crianças (OIT, 1973).

\section{OBJETIVOS E MÉTODOS}

O objetivo deste artigo é sistematizar informações sobre o funcionamento da cadeia de produção de jóias e bijuterias bem como identificar os riscos à saúde dos trabalhadores, especialmente de crianças e adolescentes que trabalham em domicílios no processo de terceirização praticado no setor.

Para obtenção de informações sobre o processo de trabalho realizado nos domicílios, após várias tentativas, conseguimos contatos com as famílias e acesso a alguns locais de trabalho, o que possibilitou conhecer o fluxo de produção bem como algumas situações de risco. Foram mantidos contatos e entrevistas abertas com representantes de indústrias e de outros elos que participam da cadeia produtiva, possibilitando agregar informações sobre o processo de produção e os vários fluxos de materiais que ali ocorrem.

Em função do receio das famílias em passar diretamente informações aos pesquisadores, optou-se por realizar a pesquisa com os estudantes da Rede Estadual de Ensino do Município de Limeira. O instrumento de coleta ou "questionário", denominado Pesquisa do Trabalho do Estudante e de sua Família, foi desenvolvido e submetido a uma seqüência de pré-testes para avaliação e sua adequação. O questionário restringiu-se a perguntas dicotômicas afirmativas ou negativas e a perguntas de múltipla escolha. 
Foram pesquisados 288 alunos de um universo de 30.800 estudantes da $5^{\mathrm{a}}$ série do ensino fundamental até o $3^{\mathrm{o}}$ ano do ensino médio inclusive o supletivo, do ano letivo de 2004 . O estudo restringiu-se a 22 de um total de 30 estabelecimentos escolares. Através de técnica amostral probabilística estratificada, dividiu-se a população em extratos homogêneos como série e escola, proporcional ao número de estudantes do estabelecimento escolar e número total dos estudantes da rede estadual de ensino do município. Deste modo trabalhou-se com um erro amostral de 5,9 \% no geral. As informações obtidas foram interpretadas através do método de análise de correspondência.

\section{Análise de Correspondência - Metodologia Estatística}

A análise de correspondência possibilita verificar as relações e associações entre as variáveis do questionário. Com este método inicialmente foi feita uma análise descritiva das questões. A seguir, procedeu-se ao estudo das relações entre as variáveis estudadas (questões), utilizando-se para tal a metodologia da análise de correspondência múltipla (CARVALHO; STRUNCHINER, 1992). O método se justifica uma vez que as variáveis tomadas são qualitativas (não paramétricas), na sua maioria, impossibilitando, então, um estudo quantitativo para explorar as relações entre as variáveis, como a análise de componentes principais. Os dados obtidos foram submetidos às técnicas estatísticas descritas, com o auxilio do "SAS", um software com conjuntos articulados de programas, desenvolvido especialmente para a análise estatística descritiva de grandes tabelas.

\section{TERCEIRIZAC̣̃̃O: UMA COMPLEXA TRANSFERÊNCIA DA INDÚSTRIA PARA OS DOMICÍLIOS E PEQUENOS INTERMEDIÁRIOS}

Na fabricação de jóias e bijuterias, é predominante a utilização de trabalhos manuais. A produção das peças brutas em sua maioria fica restrita à indústria metalúrgica, com equipamentos muitas vezes tecnologicamente ultrapassados, mas economicamente viáveis. A terceirização é a tônica principalmente nos processos de montagem, cravação, soldagem e na obtenção dos folheados por meio dos banhos de galvanoplastia.

Na Figura 1 são apresentadas as distintas possibilidades de obtenção do produto final que vão desde a criação, estampagem, montagem, banho, comercialização, distribuição até chegar ao consumidor final.

Observa-se pela figura que somente o fluxo 1 é realizado na indústria do início ao fim do processo. Os demais fluxos operam com peças brutas ou semi-prontas, repassando para fora da indústria e principalmente para os domicílios os trabalhos de montagem. Trata-se de uma intrincada rede de relações entre a indústria, os fornecedores de materiais e mão-de-obra e os contratantes dos serviços. Nota-se que existem diversos modelos de produção e consumo, considerando que os "clientes" (pessoas físicas e jurídicas) estão no meio desse processo e têm uma forte influência no atual modelo. Os clientes desempenham um papel de intermediários (atravessadores) que adquirem as peças brutas ou semi-acabadas e as distribuem para os moradores, as recolhem prontas e dão vazão ao produto final até os pontos de comercialização.

O revestimento galvânico das peças pode ser efetuado tanto dentro como fora das indústrias produtoras de "brutos". Normalmente a galvanoplastia é realizada por micro e pequenas empresas, em processos precários de trabalho e sem o tratamento dos efluentes líquidos. Segundo a Companhia de Tecnologia de Saneamento Ambiental - órgão de controle ambiental do Estado de São Paulo, das 198 empresas de jóias e bijuterias cadastradas no órgão, somente 69 são dotadas de sistema de tratamento de efluentes líquidos (CETESB 2001). Estes banhos de galvanoplastia não tratados são responsáveis por graves impactos ao meio ambiente. Segundo Ferreira (2005) foi verificada, em amostragem em diversos pontos do esgoto urbano de Limeira, onde só poderiam ser lançados efluentes de origem doméstica, a presença de produtos químicos e metais pesados muito acima dos níveis considerados normais em efluentes de origem residencial (amostra controle). Foi encontrada a presença de Cobre $(\mathrm{Cu})$ chegando a 117 vezes a amostra controle; Zinco (Zn), 325 vezes; bem como Níquel (Ni); Ouro (Au); Cromo (Cr) e Chumbo $(\mathrm{Pb})$.

\section{Montagem de peças}

A montagem e a soldagem dos componentes são realizadas essencialmente nos domicílios por trabalhadores em condições improvisadas, sujeitando um grande contingente de pessoas a riscos à sua saúde e à segurança. Trata-se de processo que expõe a população a trabalhos manuais repetitivos, com adoção de posturas forçadas de membros superiores, mediante o pagamento com base na produção obtida.

Segundo depoimentos dos representantes da cadeia produtiva, os montadores(as) mais experientes podem alcançar uma produção de aproximadamente 4.000 peças prontas por dia, enquanto a média dos trabalhadores montam uma quantidade de 3.000 peças/dia. A remuneração é de $R \$ 3,00$ a $\mathrm{R} \$ 5,00$ por milheiro montado, o que significa que a renda obtida varia de $\mathrm{R} \$ 9,00$ a $\mathrm{R} \$ 20,00$ por pessoa por dia (dados de janeiro/2005).

A cravação, outro tipo de montagem, consiste em inserir uma pedra ou componente na peça principal. Cada "cravador" pode obter uma produção média de 2.000 a 3.000 unidades cravadas por dia, obtendo uma remuneração de $\mathrm{R} \$ 8,00$ a $\mathrm{R} \$ 10,00$ por milheiro, com remuneração variando 
então de $\mathrm{R} \$ 16,00$ a $\mathrm{R} \$ 30,00 /$ dia. Ainda conforme os depoimentos, a renda mensal de um (a) montador (a) varia de $\mathrm{R} \$ 150,00$ a $\mathrm{R} \$ 250,00$, para um período de 8 a 10 horas de trabalho diário.

Matéria publicada no jornal O Estado de São Paulo com o título "Produção de jóias em Limeira emprega 6 mil crianças e jovens" baseando-se na pesquisa de mestrado de Ferreira (2005) reporta caso de uma família que trabalhava em casa com montagem de jóias e bijuterias, com envolvimento de crianças e adolescentes. O relato abaixo e a imagem da figura 2 são típicos da situação encontrada no município:

"Absorta, Janaína, de 12 anos, fixa o olhar no alicate dentro do pequeno cômodo de madeira da casa em que mora, em Limeira, a $150 \mathrm{~km}$ de São Paulo, onde passa as tardes ajustando ganchos em brincos. A garota é uma das pelo menos 6 mil crianças e adolescentes de até 17 anos do sistema estadual de ensino, segundo pesquisa da Universidade Metodista de Piracicaba (Unimep), que trabalham geralmente com as mães e os irmãos montando folheados brutos para 450 empresas do setor de bijuterias da cidade. Um contingente que pode chegar a 33 mil pessoas - levando-se em conta seus parentes - que opera clandestinamente dentro de uma cadeia produtiva que deve faturar neste ano US\$220 milhões no País, 60\% só em Limeira" (O ESTADO DE SÃO PAULO, terça-feira, 12 dezembro de 2006).

\section{Soldagem de componentes:}

No processo de soldagem são dois os tipos de solda, a solda a quente, que consiste em soldar com maçarico a gás, utilizando uma solda em pó (solda palha) e a solda a frio ou de fluxo (BRASTAK, 2005). O gás usado é o de cozinha (GLP) sendo freqüente a ocorrência de incêndios nas residências devido ao aquecimento do maçarico e à conseqüente queima das mangueiras, levando o fogo até o botijão, que queima em alta pressão, havendo ainda o risco de explosão.

A Figura 3 apresenta a foto do posto de trabalho de soldagem de jóias e bijuterias a quente.

Detalhes: Cadeira improvisada, posição estática dos ombros. Flexão contínua do cotovelo. Braços sem apoio. Flexão da coluna para aproximação do campo visual. Botijão de GLP. Risco de incêndio e explosões.

Os fluxos são aplicados na maioria dos processos de solda branda e brasagem. Brasagem é a união de metais

Figura 1: Fluxograma da rede de produção e consumo da indústria de jóias e bijuterias de Limeira-SP.

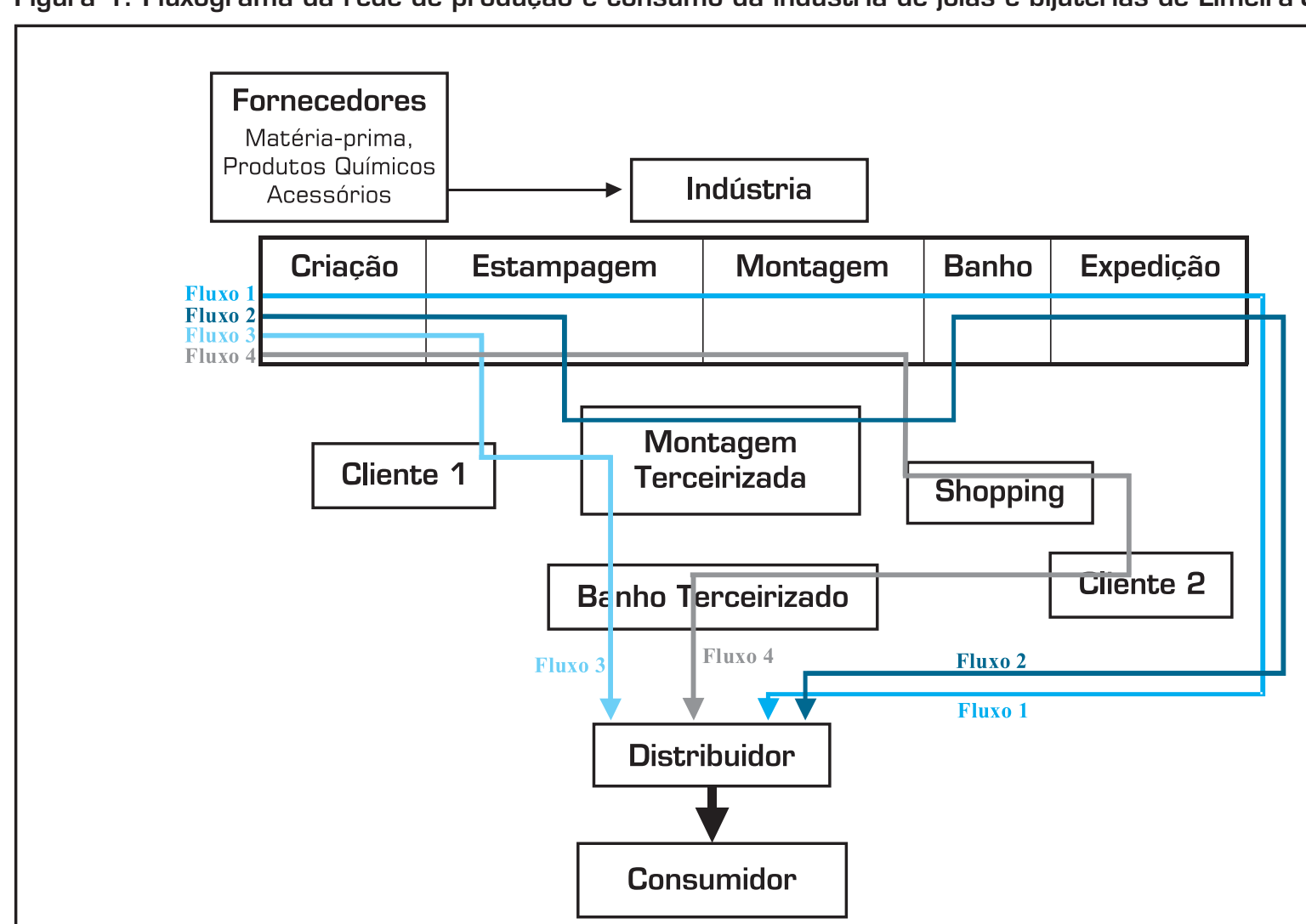


através do aquecimento abaixo da temperatura de fusão dos mesmos, adicionando-se uma liga de solda (metal de adição) no estado líquido, a qual penetra na folga entre as superfícies a serem unidas. Ao se resfriar, a junta torna-se rígida e resistente. O fluxo em geral tem como constituintes básicos compostos de boro (B) e flúor (F), na forma de ácido bórico, bórax, boratos e fluoretos.

Os fluxos, quando não empregados adequadamente, podem ser nocivos ao organismo humano. Os componentes dos fluxos podem causar irritação das vias respiratórias,

Figura 2: Trabalho de montagem envolvendo família e crianças em domicílio — foto publicada no Estado de S. Paulo na matéria supramencionada.

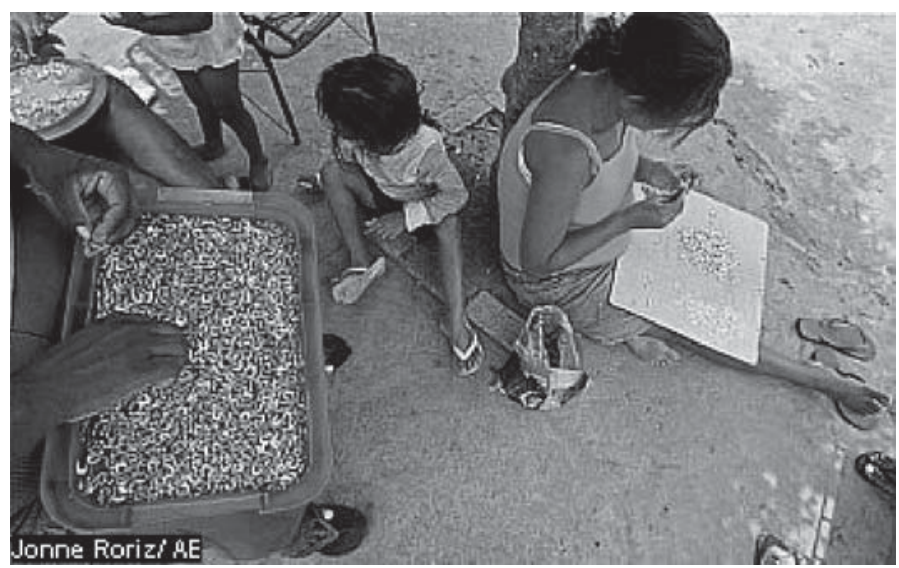

Figura 3: Trabalho de solda terceirizado para os domicílios - Limeira SP, 2005.

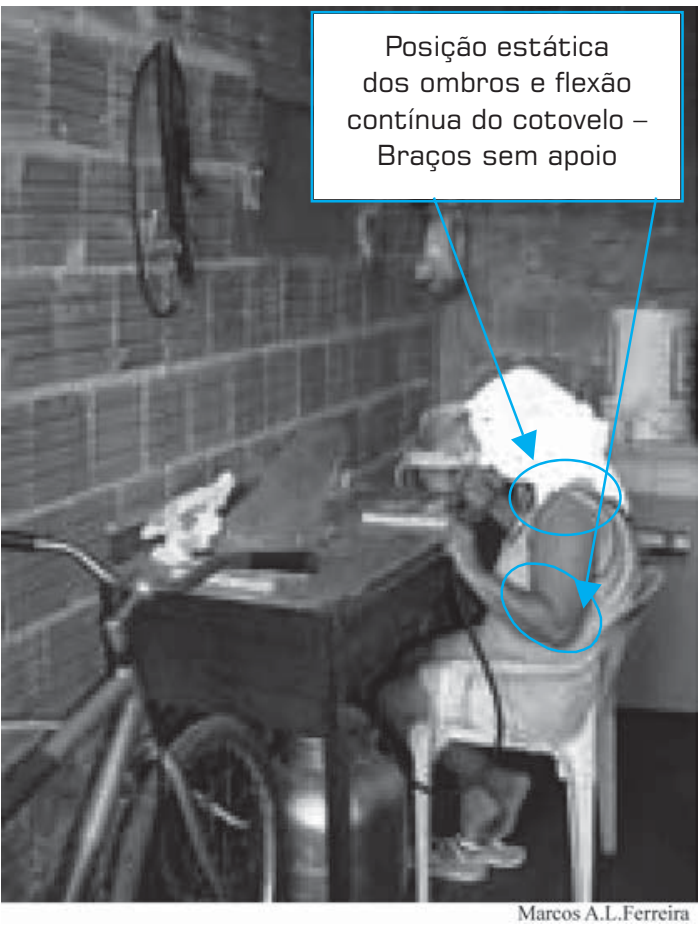


pela fumaça desprendida ou atacar a pele se permanecerem em contato com a mesma por um tempo superior a 30 minutos.

A solda a frio, que consiste em soldar com um ferro elétrico, torna necessária a utilização do Ácido clorídrico (5\% a $10 \%$ ) para o desengraxe do fio de Estanho e do material a ser soldado. Foi mencionada, por interlocutores durante a pesquisa, a ocorrência de queima da pele dos dedos das mãos de crianças com ácidos, necessitando meses para a regeneração da pele digital. Este dado foi trazido à tona novamente em 2007 durante o Seminário Municipal de Erradicação do Trabalho Infantil, conforme será mostrado no próximo item.

Os soldadores chegam a produzir em média de 1.500 a 2.000 soldagens/dia, uma produção menor que os montadores, pois esse trabalho exige maior atenção e destreza. A remuneração do trabalho de solda é maior que a dos trabalhos de montagem, variando de $\mathrm{R} \$ 10,00$ a $\mathrm{R} \$ 15,00$ por milheiro soldado. A renda de um soldador pode variar de $\mathrm{R} \$ 200,00$ a $\mathrm{R} \$ 500,00$ por mês, para um período de 8 a 10 horas por dia trabalhado (dados janeiro/2005).

\section{RESULTADOS DA PESQUISA COM ESTUDANTES DA REDE ESTADUAL DE ENSINO - ANÁLISE DE CORRESPONDÊNCIA}

Através dos 288 questionários aplicados em 22 das 30 escolas da Rede Estadual de Ensino da cidade de Limeira, foram obtidos os resultados a seguir. Cabe destacar que a Rede Estadual com as 30 escolas compreende um universo de 30.800 estudantes.

Constatou-se que $31,8 \%$ dos estudantes que responderam ao questionário possuem 17 anos ou mais e que $15,7 \%$ têm de 11 a 12 anos. A maioria dos respondentes - 55,4\% - é do sexo feminino e o restante do sexo masculino.

A maioria $(69,7 \%)$ dos estudantes faz algum trabalho doméstico, sendo que limpar a casa foi assinalado por 39,4\% dos respondentes, e cozinhar e limpar a casa por mais 19,4\%. Além dos trabalhos domésticos, 49,7\% dos estudantes afirmaram que fazem algum outro tipo de trabalho dentro ou fora de casa.

Dos estudantes que trabalham, quase a metade $(47,5 \%)$ trabalha no ramo de jóias e bijuterias, enquanto 18,4\% trabalham no comércio e outros $11,4 \%$ trabalham no ramo industrial ou em outro ramo. $\mathrm{O}$ trabalho é realizado dentro de casa por $46,2 \%$ dos estudantes e fora de casa por $68,1 \%$, indicando que $14,3 \%$ dos estudantes trabalham dentro e fora de casa. Aproximadamente $45 \%$ dos estudantes trabalham montando peças de bijuteria, ao passo que 19,2\% trabalham soldando peças de bijuteria.
A maioria dos estudantes $(62,1 \%)$ afirma que faz trabalhos repetitivos, contudo não trabalham com produtos químicos $(78,3 \%)$.

Apesar de 48,3\% dos indivíduos terem carteira profissional, apenas $23,1 \%$ têm suas carteiras profissionais assinadas.

A idade média em que os estudantes começaram a trabalhar foi de 13,2 anos, sendo que $17,1 \%$ afirmaram que começaram a trabalhar entre 7 e 11 anos, 40,7\% entre 13 e 14 anos e $26,4 \%$ entre 15 e 19 anos.

\section{Ontrariando a legislação, um grande contingente de estudantes $(8.340$ alunos] precocemente expostos a riscos de lesões no sistema osteomuscular.}

A maioria $(87,2 \%)$ dos respondentes afiança que não sofreu acidente de trabalho, e aqueles que sofreram tais acidentes citaram 4 vezes a queimadura, 3 vezes a alergia, uma vez o cair e uma vez o corte no dedo como efeitos do acidente.

Alguns estudantes $(5,9 \%)$ tiveram alguma doença causada ou piorada pelo trabalho, sendo que $13,9 \%$ dos respondentes têm irritações na pele e nos olhos relacionadas com o trabalho. Dos estudantes respondentes $32,0 \%$ têm dores nas mãos/braços e $42,1 \%$ têm dores nos ombros/pescoço/coluna. A Tabela 1 mostra os resultados destas questões.

O trabalho como forma de ajudar em casa é citado por $69,0 \%$ dos estudantes, e, além disso, 75,5\% afirmam que precisam trabalhar. Em $86,2 \%$ das vezes os estudantes disseram que gostam do que fazem no trabalho.

Em média os estudantes ganham R \$264,05 por mês, e dão $\mathrm{R} \$ 141,76$ para sua família. Cerca de 50,0\% dos estudantes ganham entre $R \$ 25,00$ e $R \$ 225,00$ por mês, contudo $24,4 \%$ ganham de $\mathrm{R} \$ 351,00$ até $\mathrm{R} \$ 1.100,00$. Aproximadamente $39 \%$ dos respondentes dão mais de $\mathrm{R} \$ 100,00$ do seu salário mensal para família.

Em 48,5\% dos casos os estudantes exercem a posição de ajudante geral no seu trabalho e em $30,0 \%$ das vezes são aprendizes. No entanto, $3,9 \%$ dos respondentes afirmam que exercem a posição de chefe no trabalho deles.

A jornada de trabalho diária de até 8 horas foi informada por $81,9 \%$ dos estudantes, entretanto, os outros $18,1 \%$ trabalham mais do que 8 horas diárias. A jornada de trabalho média informada foi de 6,9 horas.

Quase $70 \%$ dos estudantes estão trabalhando há mais de 6 meses, enquanto os outros $30,5 \%$ estão trabalhando há menos de 6 meses. 
A consciência de $87,1 \%$ dos estudantes é de que o trabalho não interfere no horário da escola, contudo 38,1\% afiançam que o trabalho dá sono e cansaço na escola.

Segundo as respostas, 79,7\% dos parentes dos estudantes trabalham fora de casa, sendo que para o pai esse valor é de $93,6 \%$, para a mãe de $65,8 \%$, para o irmão $86,8 \%$ e para a irmã 63,2\%. A indústria é a maior fonte de emprego para os parentes dos estudantes, com $23 \%$ das repostas, seguida por jóias e bijuterias com 15,6\% das respostas. Mais de 30\% dos pais trabalham na indústria, enquanto apenas $4,4 \%$ trabalham com jóias e bijuterias.

Os principais trabalhos da mãe estão ligados a jóias e bijuterias $(24,5 \%)$ e ao trabalho doméstico $(21,8 \%)$. Para o irmão os trabalhos principais são indústria $(37,3 \%)$ e comércio $(23,9 \%)$, sendo que jóias e bijuterias foi citado em $9,0 \%$. Quase um terço das irmãs (32,7\%) trabalham com jóias e bijuterias, sendo que o comércio é a segunda maior fonte de trabalho, com 23,6\%.

Tabela 1: Análise descritiva das questões relacionadas ao trabalho do próprio aluno.

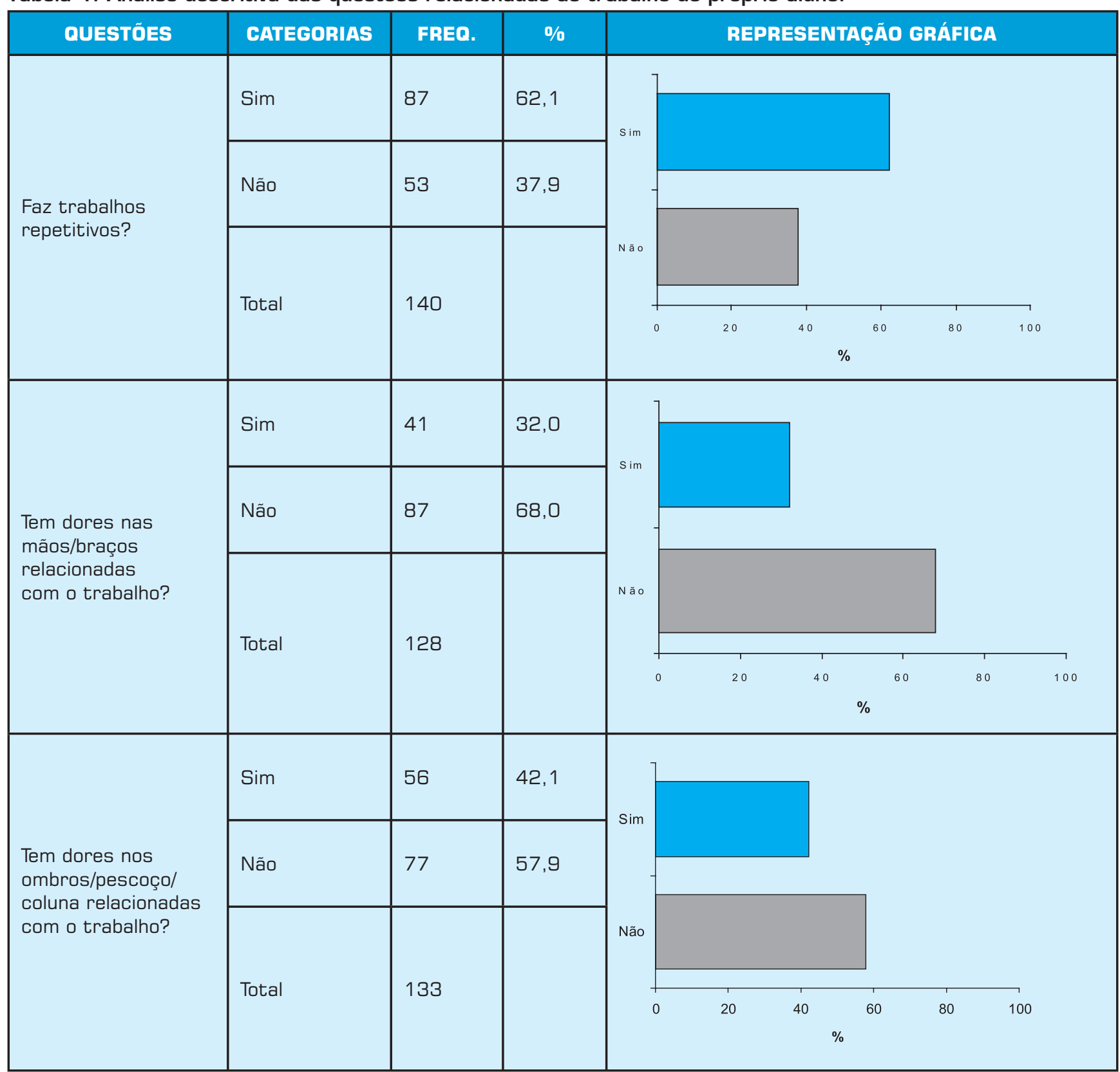


Através da análise de correspondência verifica-se que, associado ao grupo de estudantes que possui carteira assinada, localizam-se os maiores salários, a maior ajuda financeira em casa, a posição de chefe ou técnico, e o não trabalhar montando peças e bijuterias. Ao grupo de estudantes sem carteira assinada estão associados os menores salários, a menor ajuda financeira em casa, a posição de aprendiz e o trabalhar montando peças e bijuterias. Neste grupo encontrase com destaque o grupo de estudantes do sexo feminino, que é associado a dores referidas nos braços e mãos, trabalhar soldando e montando peças de jóias e bijuterias e fazer trabalhos repetitivos.

A Tabela 2 mostra o total de estudantes expostos ao trabalho com jóias e bijuterias em domicílio - Rede Estadual de Ensino (erro amostral de 5,9\%).

\section{Estimativa de população envolvida no trabalho com jóias e bijuterias}

A pesquisa com os estudantes identificou que moram no mesmo domicílio além dos estudantes 108.286 parentes. Com esses dados, sabendo-se que $24 \%$ das mães, 15,6\% dos pais, $9 \%$ dos irmãos e $32,7 \%$ das irmãs que moram nas casas dos alunos trabalham na manufatura de jóias e bijuterias, pode-se estimar que além dos estudantes 25.041 pessoas (parentes) trabalham com jóias e bijuterias no município. Somando-se aos parentes o número de estudantes (8.340) que trabalham no ramo, temos um quantitativo de 33.381 pessoas envolvidas no setor, para um erro amostral no geral de $+/-5,9 \%$. Esta estimativa é subestimada, uma vez que leva em conta que somente um irmão e uma irmã trabalham e desconsidera outros segmentos da população que não possuem alunos na rede estadual de ensino.

\section{DISCUSSÃO E PERSPECTIVAS}

Através da análise da fabricação e do fluxo de materiais da indústria de jóias e bijuterias de Limeira-SP, foi possível identificar processos produtivos instalados tanto dentro como fora das dependências das fábricas, dificultando com isso a regulação do setor, principalmente pelo fato de que partes destes processos estão pulverizadas em diversos locais do município.

O alto grau de informalidade e o receio dos trabalhadores em fornecer informações demonstram a intrincada rede formada pelas indústrias e clientes da indústria de jóias e bijuterias, levando à informalidade tanto pelas condições de trabalhos oferecidas, como pelos preços pagos. Todos os trabalhadores ficam subjugados a essa estratégia sem nenhum compromisso social, ajudada pela enorme oferta de mão-de-obra ociosa, pronta para a troca de seus trabalhos por rendimentos suficientes só para sua subsistência.

Aproximadamente $27 \%$ dos estudantes da Rede Estadual de Ensino de Limeira-SP, ou seja, 8.340 alunos, fazem trabalhos de montagem e soldagem de jóias e bijuterias em domicílio e $62,1 \%$ fazem trabalhos repetitivos. O trabalho infantil é caracterizado pelo grande número de estudantes na faixa etária de 11 a 17 anos, o que chega a aproximadamente $20 \%$ desses estudantes, uma quantidade expressiva e preocupante de aproximadamente 6.000 crianças e adolescentes, com uma jornada média diária de 6,9 horas, caracterizando, indiscutivelmente, exploração de mão-de-obra infantil.

Concordando com as considerações de Assunção e Dias (2002), nada mais cruel do que não favorecer e bloquear as capacidades de criação de um indivíduo. Se para os adultos as longas jornadas são motivos de queixas de privação de

Tabela 2: Quantidade de estudantes da Rede Estadual que trabalham e trabalham com jóias e bijuterias Limeira, 2004

\begin{tabular}{|c|c|c|c|}
\hline ESTUDANTES DA REDE ESTADUAL DE ENSINO & $\begin{array}{l}\text { QUANT. } \\
\mathbf{N}=288\end{array}$ & $\begin{array}{l}\text { PORGENT. } \\
\text { (\%) }\end{array}$ & $\begin{array}{l}\text { POPULAÇÃO DE } \\
\text { ESTUDANTES QUE } \\
\text { TRABALHA(*) } \\
\text { (ERRO 5,9\%) }\end{array}$ \\
\hline Estudantes que trabalham & 144 & $50,0 \%$ & 15.400 \\
\hline Estudantes menores de 17 anos que trabalham & 77 & $26,73 \%$ & 8.233 \\
\hline $\begin{array}{l}\text { Estudantes menores de } 17 \text { anos que trabalham - jóias e } \\
\text { bijuterias }\end{array}$ & 56 & $19,44 \%$ & 5.987 \\
\hline Estudantes maiores de 17 anos que trabalham & 67 & $23,26 \%$ & 7.164 \\
\hline $\begin{array}{l}\text { Estudantes maiores de } 17 \text { anos que trabalham - jóias e } \\
\text { bijuterias }\end{array}$ & 22 & $7,63 \%$ & 2. 350 \\
\hline Total de estudantes que trabalham com jóias e bijuterias & 78 & $27,08 \%$ & 8.340 \\
\hline
\end{tabular}

"Universo de 30.800 estudantes 
lazer, de leitura, de vida afetiva, para as crianças e adolescentes o agravante deste quadro são os efeitos oriundos do bloqueio de tempo para o contato com universos distintos que ofereçam estímulos ao desenvolvimento de suas potencialidades.

A maioria dos trabalhos terceirizados, informais e em domicílio é realizada por pessoas do sexo feminino, $24,5 \%$ das mães e $32,7 \%$ das irmãs dos estudantes, todas sem nenhum tipo de garantia de proteção social ou trabalhista.

O gesto repetitivo das montagens, soldagens e cravação de peças pode chegar a 4.000 peças por trabalhador por dia. Esta produção se associa às queixas referidas de dores nos membros superiores, mãos, braços, pescoço e ombros que estão associadas ao trabalho repetitivo e ao trabalhar com jóias e bijuterias, com predominância no grupo feminino (32\% dos estudantes têm dores nas mãos/braços e 42,1\% deles têm dores nos ombros/pescoço/coluna).

Pelo que referem os estudantes, suas queixas de dores e outros sintomas conclui-se que os trabalhos de manufatura de jóias e bijuterias caracterizam-se como trabalhos perigosos à saúde, que não poderiam ser realizados por trabalhadores com idade inferior a 18 anos, como determinam o artigo 7, Inciso XXXIII da Constituição Federal, e as orientações da Convenção 138 de 1996 da OIT.

Exemplo dos riscos e das lesões que estão acontecendo na cidade começa a vir à tona, como o caso reportado pelo supervisor da Diretoria Regional de Ensino de Limeira, Antonio Cardoso de Sena, durante o 1 Seminário Municipal para Erradicação do Trabalho Infantil, que aconteceu na Câmara Municipal em 24/08/2007, organizado pela Comissão Municipal de Erradicação do Trabalho Infantil. No evento o supervisor relata o caso de 11 estudantes, com idades entre 15 e 16 anos, que perderam as digitais em razão da exposição excessiva a produtos químicos nas atividades de soldagem de jóias. Conforme relata o Jornal Gazeta de Limeira, o fato de estudantes perderem suas impressões digitais nunca ocorreu na história da Diretoria de Ensino e o quadro é de tal relevância que causou mobilização. A tentativa é de

Os resultados indicam a existência de um grande contingente de estudantes (8.340 alunos) precocemente expostos a riscos de lesões no sistema osteomuscular.

As Lesões por Esforços Repetitivos são fenômenos complexos e reconhecidamente multifatoriais. Os determinantes relacionados ao trabalho são: organização da produção e da empresa; organização do trabalho e das tarefas, concepção dos equipamentos e ferramentas. Os fatores de risco para o surgimento de tais lesões são os fatores biomecânicos (esforço, posturas forçadas, gesto e o tamanho curto do ciclo de trabalho) e os psicossociais (insatisfação, percepção negativa do trabalho etc) (ASSUNÇÃO, 1995; MAENO et al., 2001) .

A situação encontrada em Limeira apresenta-se como ambiente propício para o surgimento de lesões desta natureza uma vez que estão presentes os determinantes e os fatores de risco apontados. Chama atenção a forma de remuneração adotada baseada no pagamento por produção. O estímulo financeiro adotado contraria a legislação vigente, uma vez que a Norma Regulamentadora ํㅡㄴ 17 - Ergonomia - do Ministério do Trabalho e Emprego (BRASIL, 1990) indica que nas atividades que exijam sobrecarga muscular estática ou dinâmica do pescoço, ombros, dorso e membros superiores e inferiores, todo e qualquer sistema de avaliação de desempenho para efeito de remuneração e vantagens de qualquer espécie deve levar em conta as repercussões sobre a saúde dos trabalhadores. garantir, através da Secretaria da Justiça e Cidadania do Estado, que os jovens tenham direito ao documento mais comum e necessário a um cidadão - o RG - impossível de ser emitido sem as impressões digitais. A Diretoria pretende enviar um relatório para a Secretaria de Justiça "pedindo orientação nesse caso, porque eles precisam ter documentos" (GAZETA DE LIMEIRA, 2007).

Apesar da maioria dos estudantes afirmar através dos questionários que o trabalho não interfere no horário da escola, 38,1\% afirmam que o trabalho dá sono e cansaço na escola. Segundo Assunção e Dias (2002), freqüentando a escola cansados e com sono, pode-se pensar que as crianças não terão força para responder aos estímulos da aprendizagem. Não sendo completo o aprendizado, mais tarde estas pessoas continuarão na periferia das situações de trabalho, pois não terão as qualificações e nem os pré-requisitos para desenvolvê-las, continuando a se submeter às condições penosas e menos qualificadas, tendendo a reproduzir a situação de suas famílias. Em situação de trabalho fragmentado sob fortes exigências físicas, crianças e adolescentes não estão tendo favorecidas as condições necessárias para o desenvolvimento de competências que permitirão, mais tarde, adquirir outras. Fazendo referência a uma citação de Pierrard $^{3}$, as autoras chamam a atenção para uma frase de um antigo trabalhador infantil que menciona o "profundo silêncio mental que sustenta a pobreza operária", ilustrando as conseqüências do bloqueio das capacidades de aprendi- 
zagem e de criatividade durante a fase de desenvolvimento em que os jovens se encontravam trabalhando.

As informações trazidas no estudo indicam a necessidade de se ampliar o conhecimento e o debate sobre as repercussões anti-sociais decorrentes do modo de produção adotado pelo setor produtivo, bem como a necessidade de se buscar a regulação do mesmo através de políticas públicas e alternativas sustentáveis para a produção de jóias no Município de Limeira-SP.

No final de 2006, a divulgação dos dados da pesquisa de mestrado (FERREIRA, 2005) teve forte repercussão na imprensa local e nacional e motivou a criação de uma Comissão Municipal de Erradicação do Trabalho Infantil em Limeira. Esta comissão vem agregando representantes do poder público e da sociedade civil, incluindo a representação patronal, em busca de alternativas para superar a atual situação. Entre estas iniciativas coube destaque ao 1o Seminário Municipal anteriormente citado, onde participaram, entre outros, o Prefeito Municipal, representantes do setor de fabricação de jóias e bijuterias (Sindicato e associação patronal), representantes da Organização Internacional do Trabalho (OIT), do Fórum e do Conselho Nacional de Erradicação do Trabalho Infantil e de vários órgãos vinculados ao tema. O Seminário produziu um Protocolo de Intenções pela Erradicação do Trabalho Infantil em Limeira e Região. O Protocolo deixa claro o compromisso público dos participantes na busca de alternativas sustentáveis que ultrapassem as políticas compensatórias e incidam sobre a dinâmica produtiva que leva as atividades produtivas até as residências.

Na esfera pública, foi proposta a implantação, com apoio do Centro de Referência em Saúde do Trabalhador Regional Piracicaba, de sistema de notificação dos casos através do Sistema Único de Saúde, para aprimorar o diagnóstico da situação de saúde desta população exposta aos riscos aqui identificados. Neste programa é importante o mapeamento da população exposta, a notificação dos agravos relacionados ao trabalho, o afastamento da popu- lação precocemente exposta aos riscos, além das ações de promoção e prevenção.

Outras propostas foram elaboradas para os setores da educação visando criar uma consciência crítica nos professores e na comunidade para a recusa ao trabalho nas condições atuais.

Junto ao setor empresarial outras iniciativas são necessárias para o redesenho da cadeia produtiva, de modo a evitar e controlar as terceirizações para que o trabalho não chegue às residências. A questão ambiental, referente aos lançamentos de produtos químicos e metais na rede de esgotos sem tratamento, que por questão de espaço não foram abordados neste texto, revelam um outro lado da mesma insustentabilidade, que se não controlada pode, entre outras conseqüências ambientais e sociais, comprometer a viabilidade do pólo produtivo perante os mercados mais exigentes, principalmente do Mercado Comum Europeu.

Mesmo não sendo objeto e foco do presente estudo, as reflexões e dados aqui revelados reforçam a necessidade de um redesenho da cadeia produtiva do pólo de jóias e bijuterias de Limeira. A despeito de possíveis prejuízos ao setor econômico que a eliminação da terceirização predatória possa trazer de imediato, esta nos parece ser a única via para eliminar a exposição precoce de crianças e adolescentes ao trabalho perigoso. Quando colocados diante de uma balança como esta, deve prevalecer a defesa da vida. Neste sentido, consideramos necessários novos estudos junto ao Arranjo Produtivo Local de Jóias e Folheados de Limeira, para aprofundar as alternativas e mudanças em busca do equilíbrio socioambiental do setor.

Através do esforço coletivo, acreditamos ser possível reverter o quadro atual e superar a precarização do trabalho e a degradação ambiental, vislumbrando para o futuro um modelo de desenvolvimento que não se subordine à lógica atualmente hegemônica, que resulta em ausência de cidadania, assim mantida por um aparelho de estado mínimo e omisso.

\section{Artigo recebido em 07/02/2007} Aprovado para publicação em 02/01/2008

\footnotetext{
- Notas

1. Dados e informações do relatório do Projeto PML/SEBRAE/ACIL (1998).

2. Convenção no 138 da Organização Internacional do Trabalho (OIT) é uma consolidação de princípios, que tem sido gradualmente estabelecida em vários instrumentos recentes e se aplica a

todos os setores de atividade econômica, estando ou não a criança empregada por salário (OIT,1973).

3. PIERRARD, P. Enfants et jeunes ouvriers en France (XIX-XX siècle). Paris: Les éditions ouvrières, 1987, citado por ASSUNÇÃO e DIAS (2002).
} 


\section{- Referências}

ASSUNCÃO, A. A.; DIAS, E. C. Trabalho precoce: possíveis efeitos sobre o desenvolvimento das crianças e adolescentes. Belo Horizonte: Devir, v. 1, n. 2, p. 61- 76, 2002.

ANDRADE GONÇALVES, M.; THOMAZ Jr. A. Informalidade e precarização do trabalho: uma contribuição a geografia do trabalho. Scripta Nova, Revista Electrónica de Geografia y Ciencias Sociales. Universidad de Barcelona, v. VI, n. 119(31), 2002. http://www.ub.es/geocrit/ $\mathrm{sn} / \mathrm{sn} 119-31 . \mathrm{htm}$

ASSUNÇ̃̃O, A. A. Sistema Músculo Esquelético: Lesões por Esforços Repetitivos (LER). In MENDES, R. (org). Patologia do Trabalho. Rio de Janeiro: Atheneu, p. 173-212, 1995

BRASIL, Lei 8.096 de 13 de julho de 1990. Dispõe sobre o Estatuto da Criança e do Adolescente e dá outras providências. http://www.planalto.gov.br/ccivil_03/ Leis/L8069.htm

BRASTAK, Boletim Técnico Fluxos para solda branda e brasagem. Rev. 02, acesso em 31/05/2005 <www.brastak.com. br $>$.

CAMPOS, L; CHIESA, A. M; MOTTA, R. M. M.; WESTPHAL, M.F. Percepção das crianças, pais e professores sobre o trabalho infanto-juvenil nas bancas de calçados de Franca - SP. In: WESTPHAL, M. F. (coord.). O compromisso da saúde no campo do trabalho infanto-juvenil: uma proposta e atuação. São Paulo, cap. 2 , p. $13-37,1999$

CARVALHO, M. S.; STRUNCHINER, C. J. Correspondence Analisys: An Apllication of the Method to the Evaluation of Caccination Services. Cad. Saúde Públ. Rio de Janeiro, 8(3), p. 287-301, jul. set., 1992.

FERREIRA. M. A. L. Estudo dos Riscos a Saúde do Trabalhador e ao Meio Ambiente na Produção de Jóias e Bijuterias de Limeira$S P$. UNIMEP, Piracicaba. Dissertação de Mestrado. Programa de Pós-Graduação em Engenharia de Produção. 1995.

GAZETA DE LIMEIRA. “Trabalho infantil. Uso de solda faz 11 menores perderem impressão digital". Paginas 1 e 2 , dia 25/08/2007. Jornal diário, Limeira SP. Disponível no site: < http://www.gazetadelimeira.com.br/site/index $>$.

ILO. 1998. Child labour: targeting the intolerable. International Labour Conference - Report VI (1) - 86th Session. International Labour Organization, Geneva.
KASSOUF, A. L. Aspectos socioeconômicos do trabalho infantil no Brasil. Unesco, Ministério da Justiça, 2002.

KASSOUF, A. L. O Brasil e o Trabalho Infantil no início do Seculo 21. OIT Brasil. Brasília, 2004. 82 p. Disponível em < http://www. oit.org.pe/ipec/documentos/ti_br_seculo21.pdf>.

LAVINAS, L.; SORJ, B.; LINHARES, L.; JORGE, A. Trabalho a domicilio: novas formas de contratação, 1998. <www.ilo. org/public/portugue/employment/strat/ publ/iddp30.htm $>$.

MAENO, M. ALMEIDA, I. M; MARTINS, M. C. et al. Lesões Por Esforços Repetitivos (LER) Distúrbios Osteomusculares Relacionados ao Trabalho (DORT). Normas e Manuais Técnicos no 103, Ministério da Saúde. Brasil, 2001. Disponível no site: <www. saude.gov.br/publicações >

MARCONDES, E et al. Os fatores ambientais (Ecopediatria). In: MARCONDES, E. Pediatria Básica. São Paulo: Sarvier, p. 9-25, 1992. Citado por ASSUNÇ̃̃O e DIAS, 2002

NIOSH - Special hazards review - Child Labor Research Needs. Recommendations from the NIOSH child labor work team,
Aug 1997 [Available in www.cdc.gov/ niosh/97-143b.html]. Acessado em agosto 2007

O ESTADO DE SÃO PAULO. Produção de jóias em Limeira emprega 6 mil crianças e jovens. Jornal diário: terçafeira, 12 dezembro de 2006. Mário Tonocchi, Especial para O ESTADO, Limeira. Acessível em: < http://www. estado.com.br/editorias/2006/12/12 ger-1.93.7>. 2006

ORGANIZACÃO INTERNACIONAL DO TRABALHO - OIT. Sobre a Idade Mínima de Admissão ao Emprego. Genebra. 1973.

PREFEITURA MUNICIPAL DE LIMEIRA - Informações sobre o Município. Fonte Censo Demográfico de 2000, IBGE, disponível em http://www.limeira.sp.gov.br/ municipio. Acesso em: nov. 2006

RAIS - Relatório Anual de Informações Sociais - INSS, 2000

SUZIGAN, W. et al. Aglomerações industriais no Estado de São Paulo. In: Anais do XXVIII Encontro Nacional de Economia. Campinas, ANPEC, 2000.

\section{- Agradecimentos}

Dedicamos este artigo aos professores e à Direção Estadual de Ensino (Regional de Limeira) pelo apoio e acolhimento à pesquisa realizada. O artigo parte dos dados obtidos na dissertação de Mestrado de Marcos Libardi Ferreira sob orientação do Prof. Dr. Rodolfo A.G. Vilela, concluída em agosto de 2005, junto ao Programa de Pós-Graduação em Engenharia de Produção da UNIMEP. O estudo teve aprovação do Comitê de Ética da Universidade.

\section{Sobre os autores}

\section{Rodolfo Andrade de Gouveia Vilela D.Sc}

Universidade Metodista de Piracicaba, CEREST Piracicaba

End.: Rod. Sta. Bárbara/Iracemápolis, Km 1. - Sta. Bárbara d'Oeste - SP - CEP 13450-000

Tel.: (19) 3455-2311

E-mail: ravilela@unimep.br

Centro de Referência em Saúde do Trabalhador - CEREST / Secretaria Municipal de Saúde de Piracicaba Rua São Francisco de Assis, 983 - CEP 13400-590

Tel.: (19) 3434-6337 - 3435-3505

Email: ravcerest@yahoo.com.br

\section{Marcos Antonio Libardi Ferreira M.Sc.}

Eng. de Produção - Consultor

End.: R. São João, 40 - Bairro dos Alemães - Piracicaba - SP - CEP 13416-585

Tel.: (19) 3433-7402

E-mail: malfeaep@hotmail.com 